\title{
Relative tropospheric photolysis rates of HCHO and HCDO measured at the European Photoreactor Facility
}

Karen L. Feilberg, ${ }^{1}$ Matthew S. Johnson, ${ }^{1}$ Asan Bacak, ${ }^{2}$ Thomas Rockmann ${ }^{2}$ and Claus J. Nielsen ${ }^{3 *}$

${ }^{1}$ Copenhagen Center for Atmospheric Research, Department of Chemistry, University of Copenhagen, Universitetsparken 5 DK-2100 Copenhagen OE, Denmark, ${ }^{2}$ Institute for Marine and Atmospheric Research Utrecht (IMAU), Princetonplein 5, 3584 CC Utrecht, PO Box 80000, 3508 TA Utrecht, The Netherlands, and ${ }^{3}$ Centre for Theoretical and Computational Chemistry, Department of Chemistry, University of Oslo, Pb. 1033 - Blindern 0315 Oslo, Norway

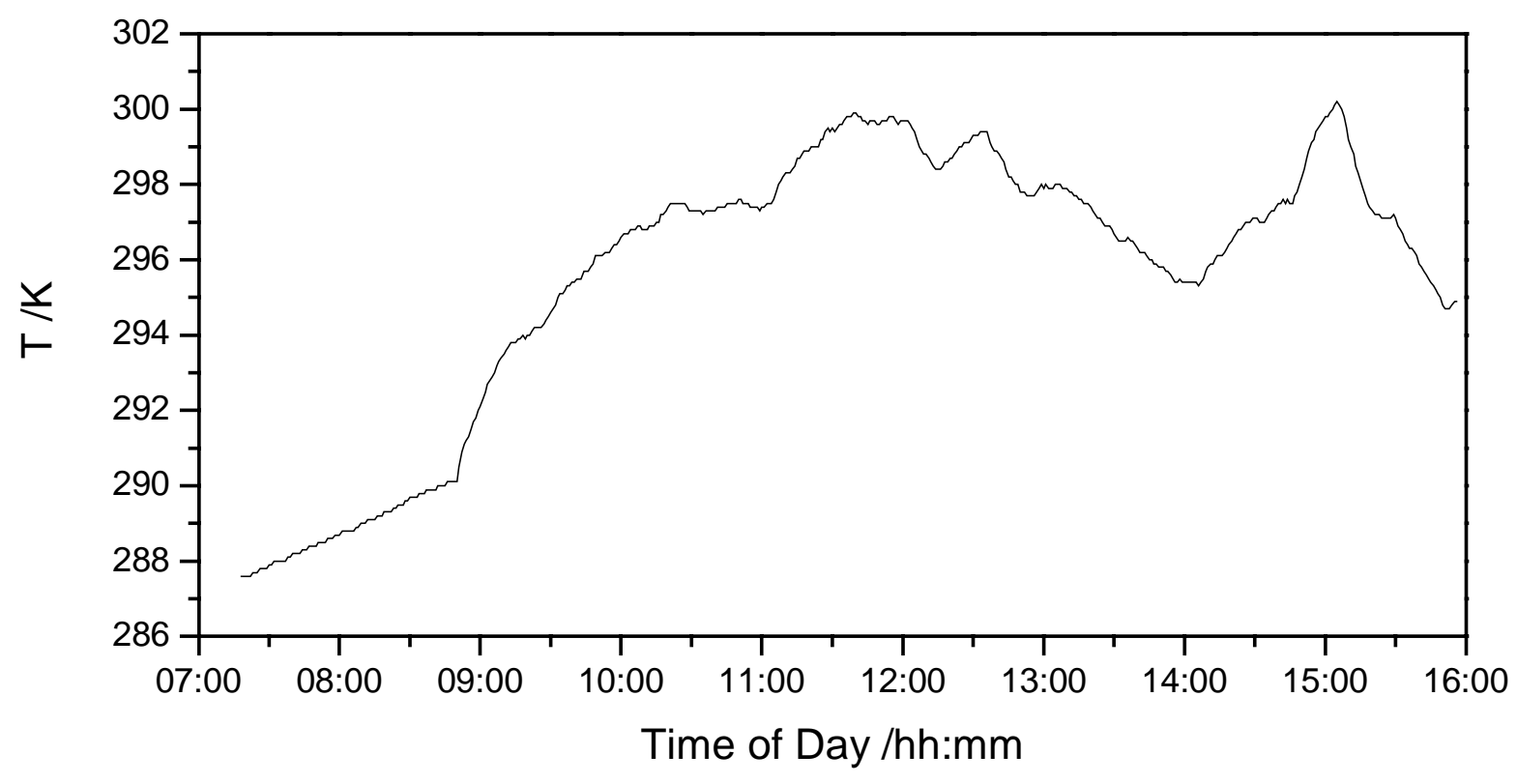

Figure S1. Temperature in the European Photoreactor Facility, chamber A, during the experiment on May 26, 2004. 


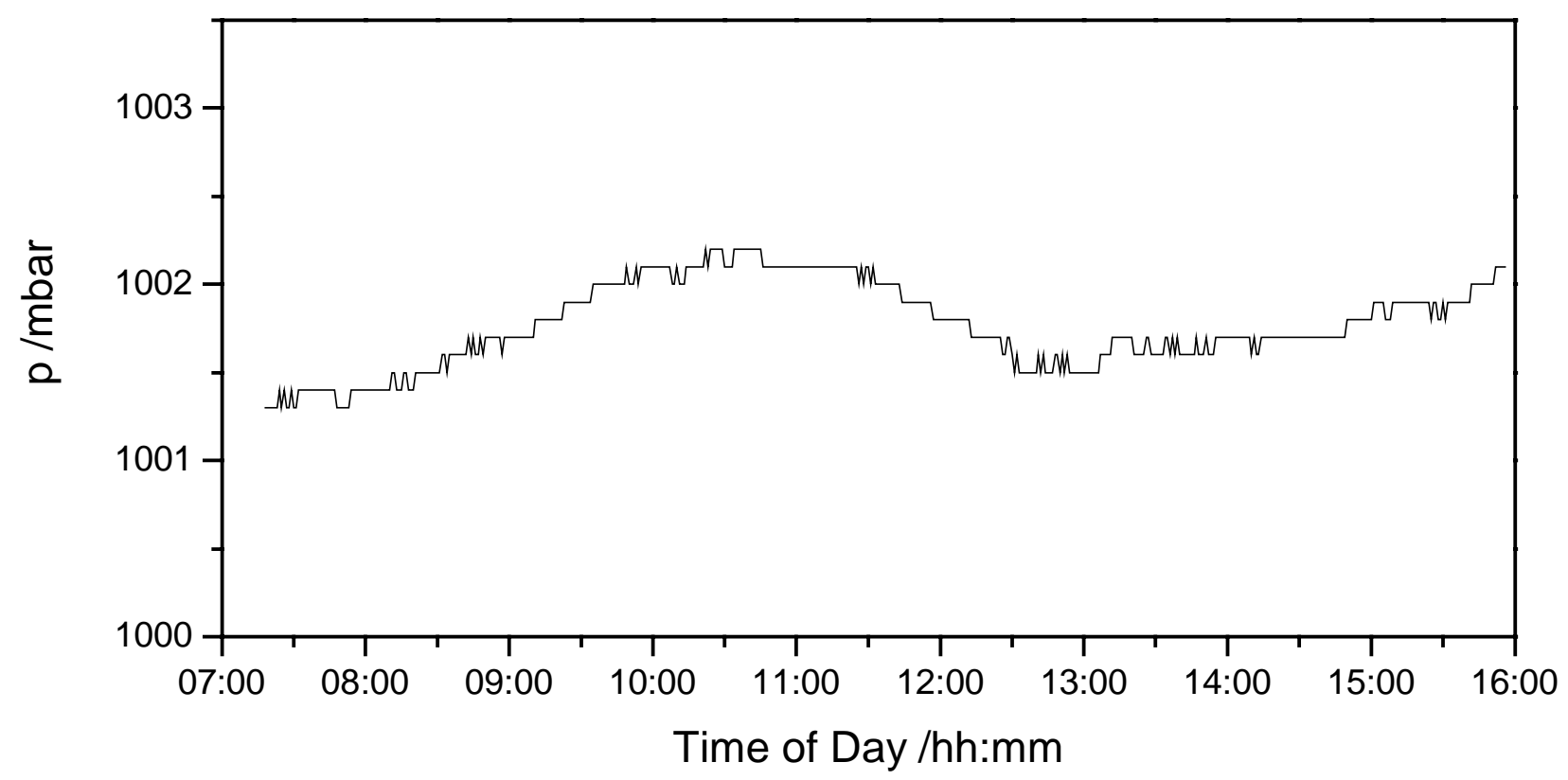

Figure S2. Pressure in the European Photoreactor Facility, chamber A, during the experiment on May 26, 2004.

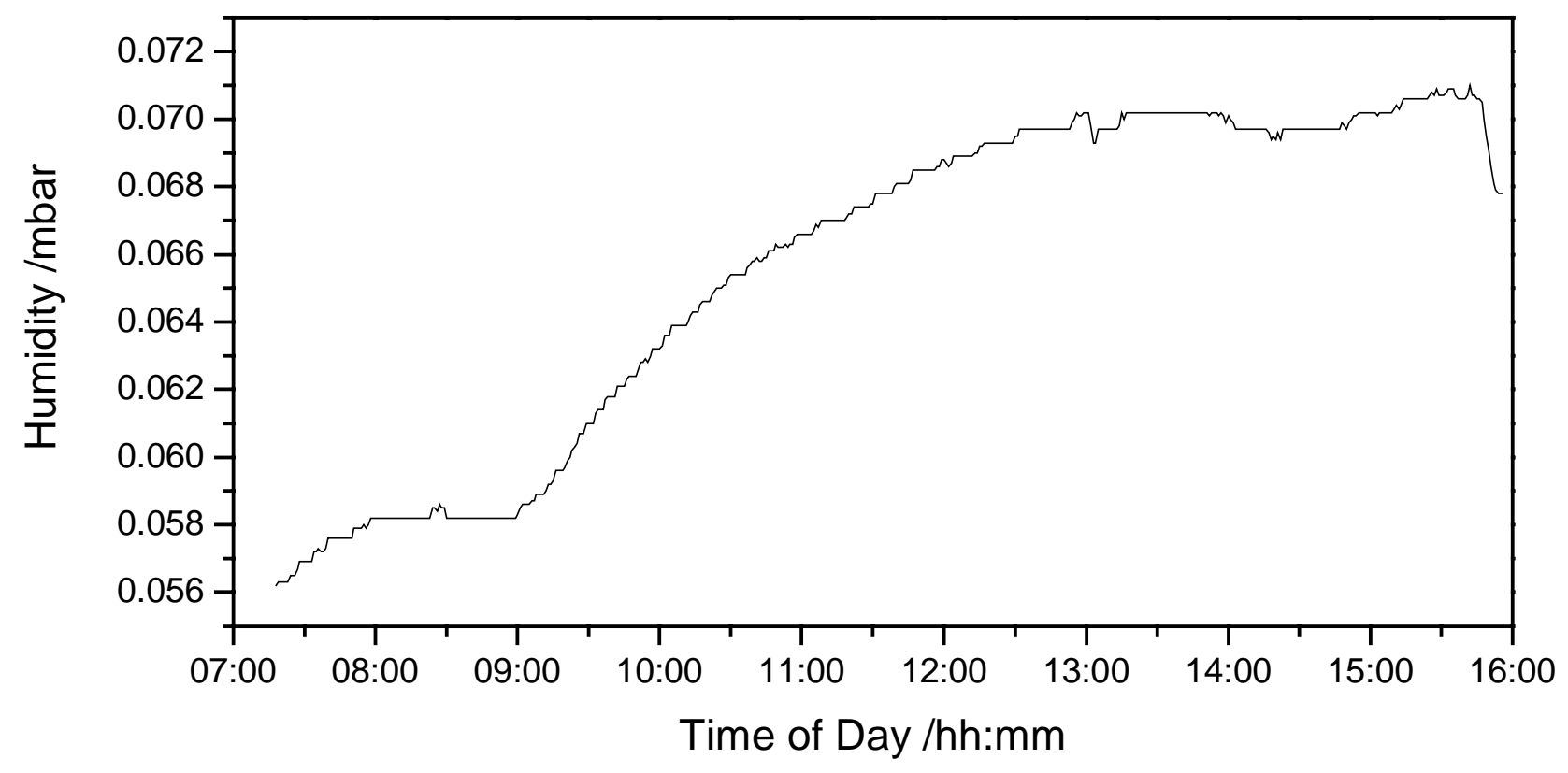

Figure S3. Humidity in the European Photoreactor Facility, chamber A, during the experiment on May 26, 2004. 


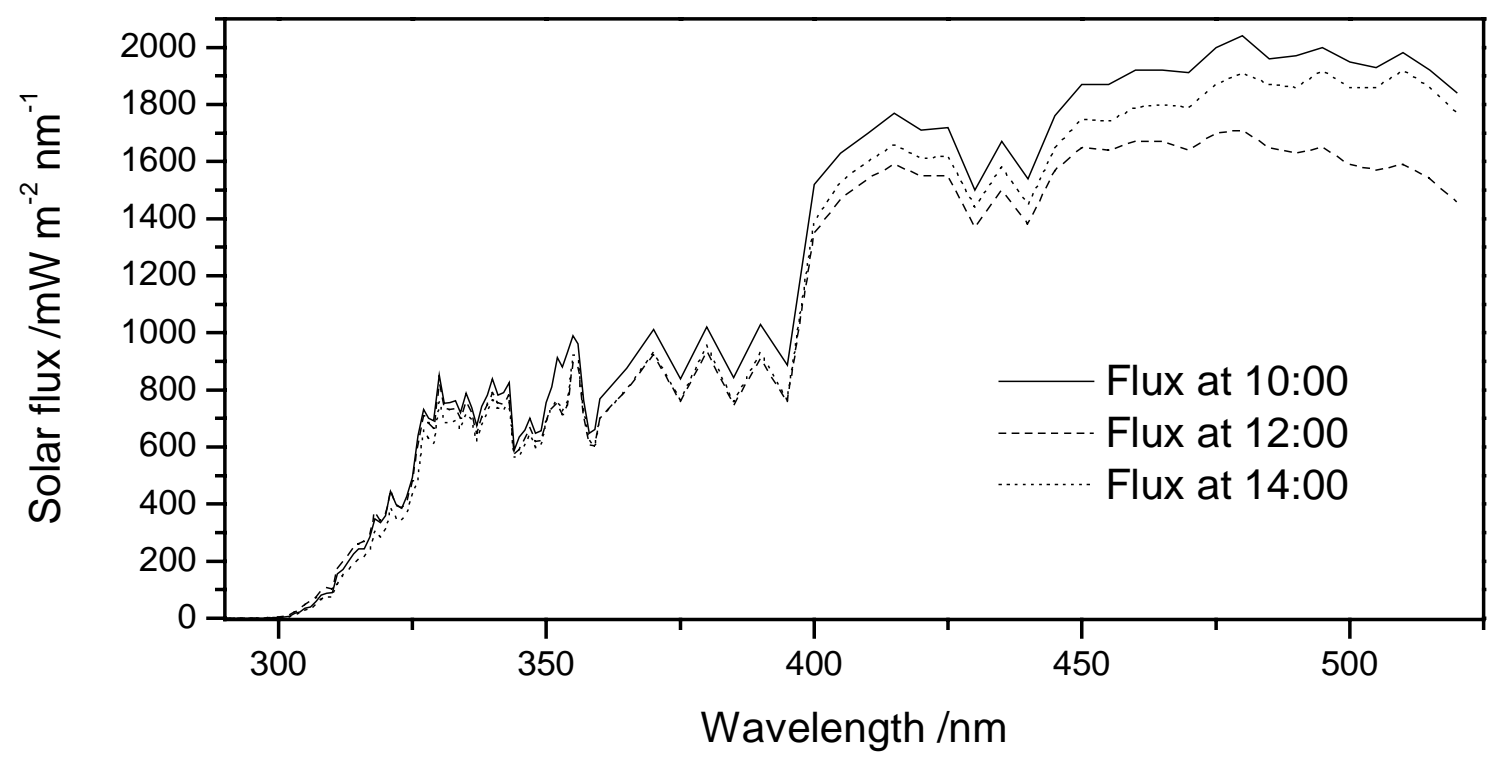

Figure S4. Solar flux in the European Photoreactor Facility, chamber A, at 10:00, 12:00 and 14:00 during the experiment on May 26, 2004.

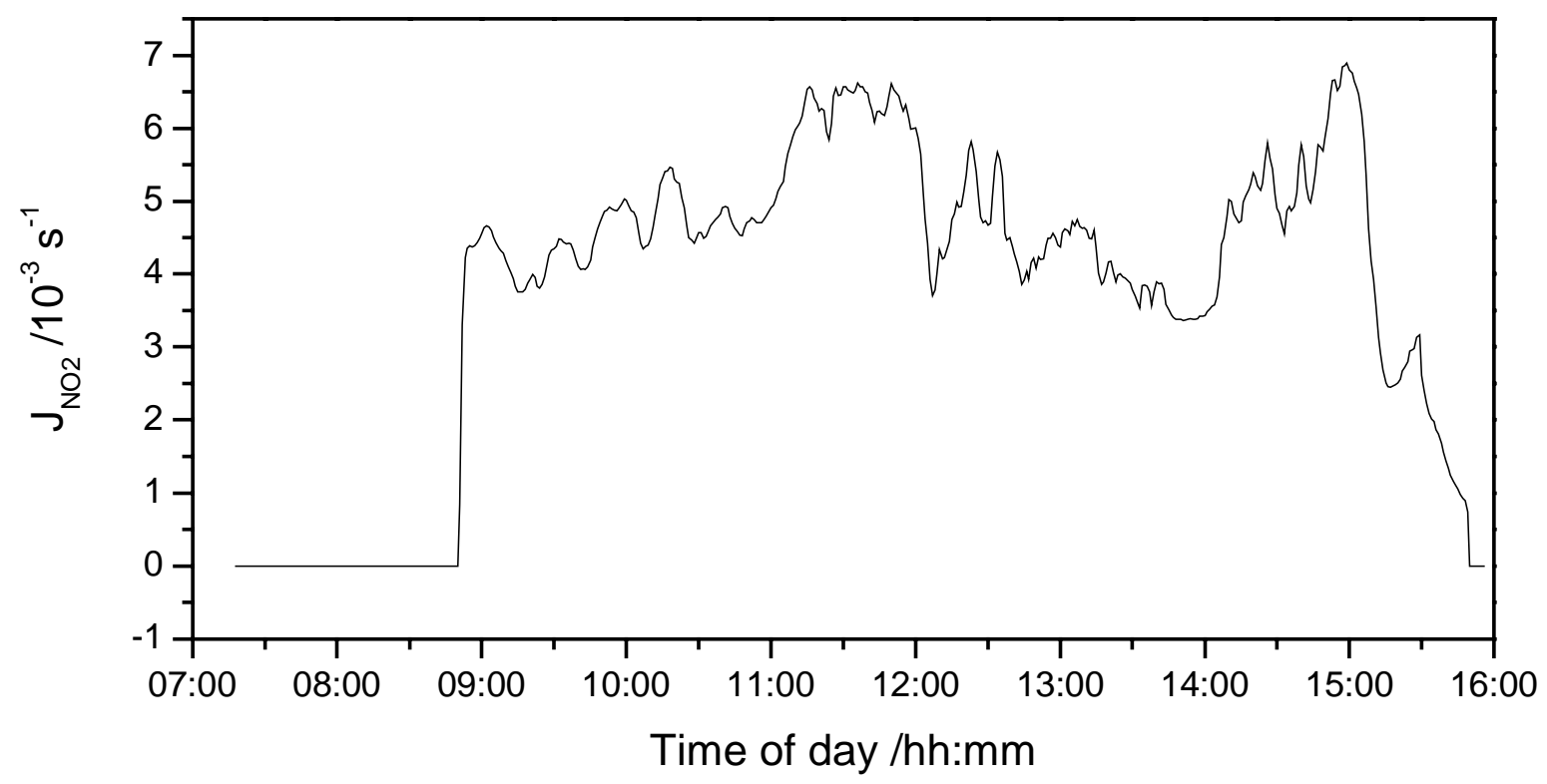

Figure S5. $j_{\mathrm{NO} 2}$ measured inside the European Photoreactor Facility, chamber A, during the experiment on May 26, 2004. The chamber canopy was opened 8:50. 


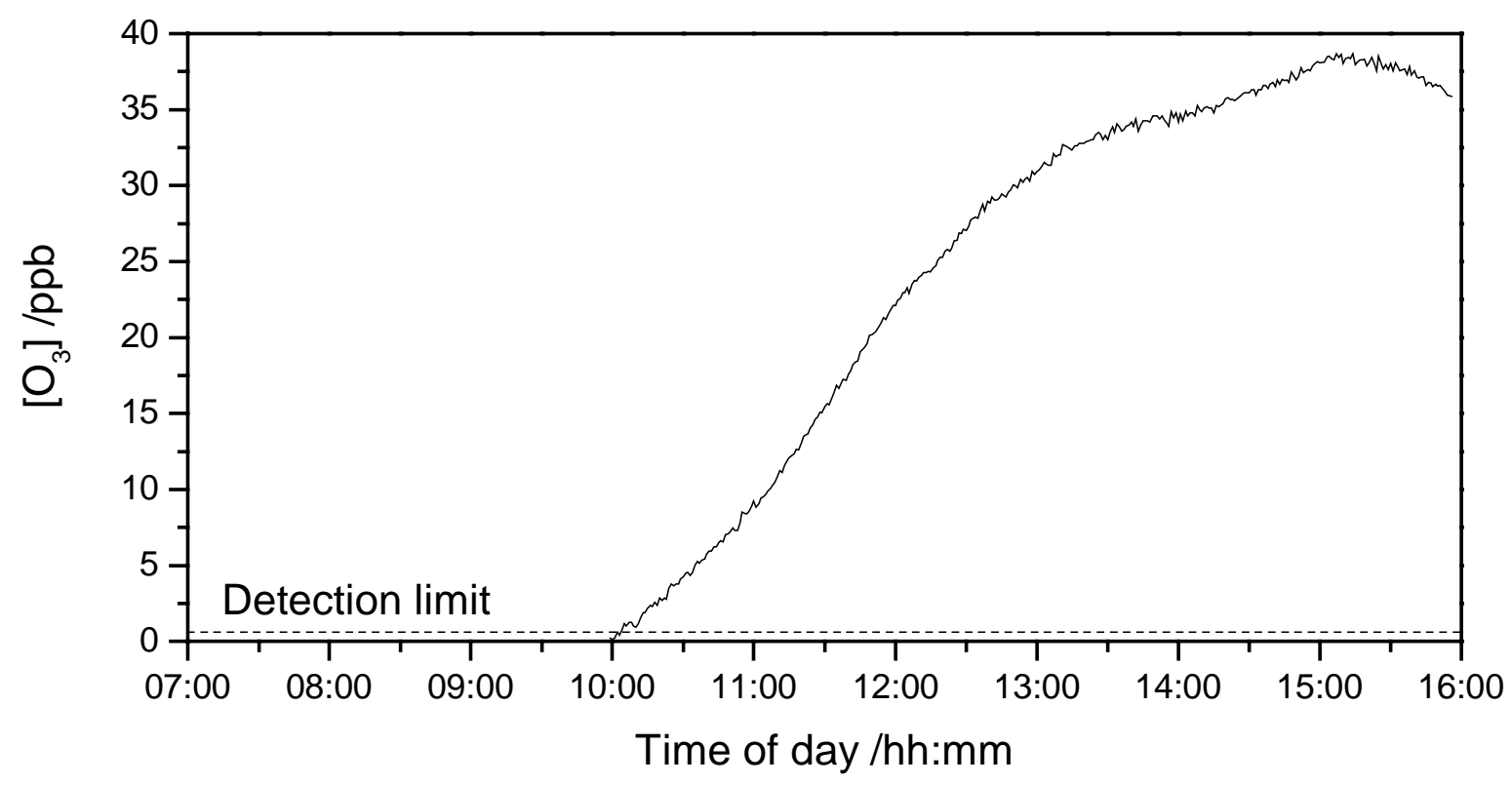

Figure S6. Ozone in the European Photoreactor Facility, chamber A, during the experiment on May 26,2004 . The detection limit of the ozone monitor is $0.65 \mathrm{ppm}$.

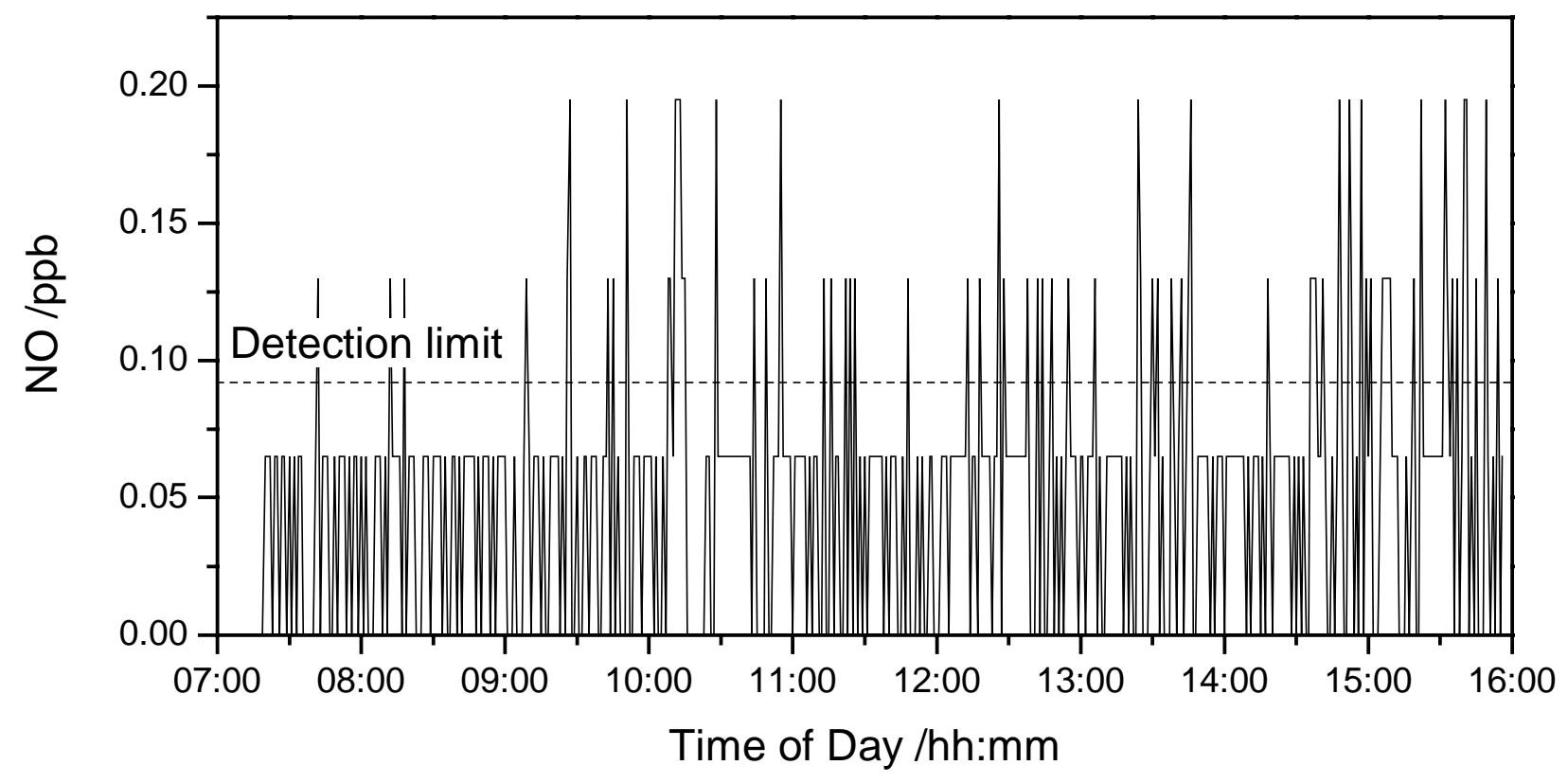

Figure S7. NO in the European Photoreactor Facility, chamber A, during the experiment on May 26, 2004. The detection limit of the NO monitor is $0.092 \mathrm{ppb}$. 


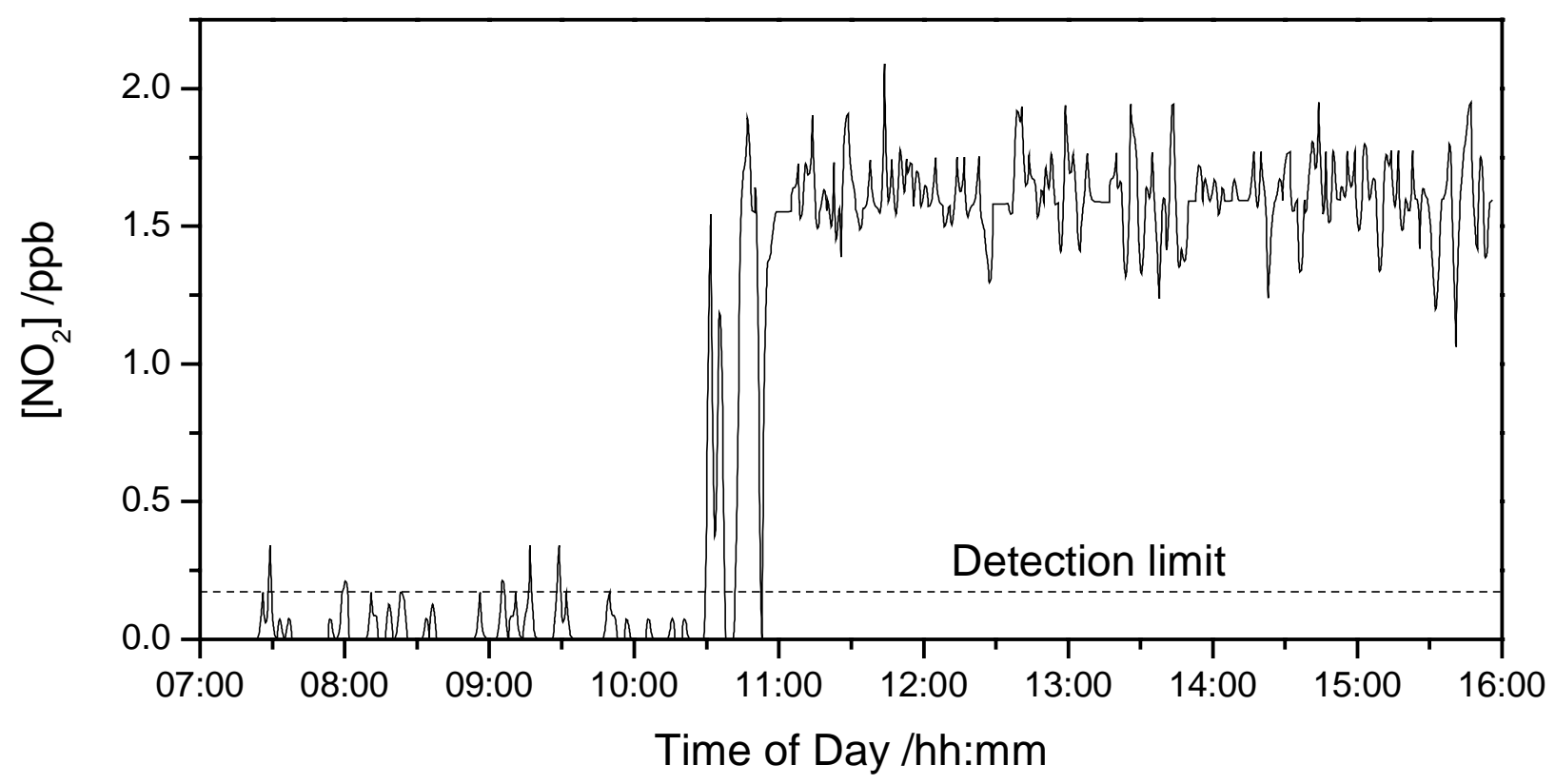

Figure S8. $\mathrm{NO}_{2}$ in the European Photoreactor Facility, chamber A, during the experiment on May 26, 2004. The detection limit of the $\mathrm{NO}_{2}$ monitor is $0.172 \mathrm{ppb}$.

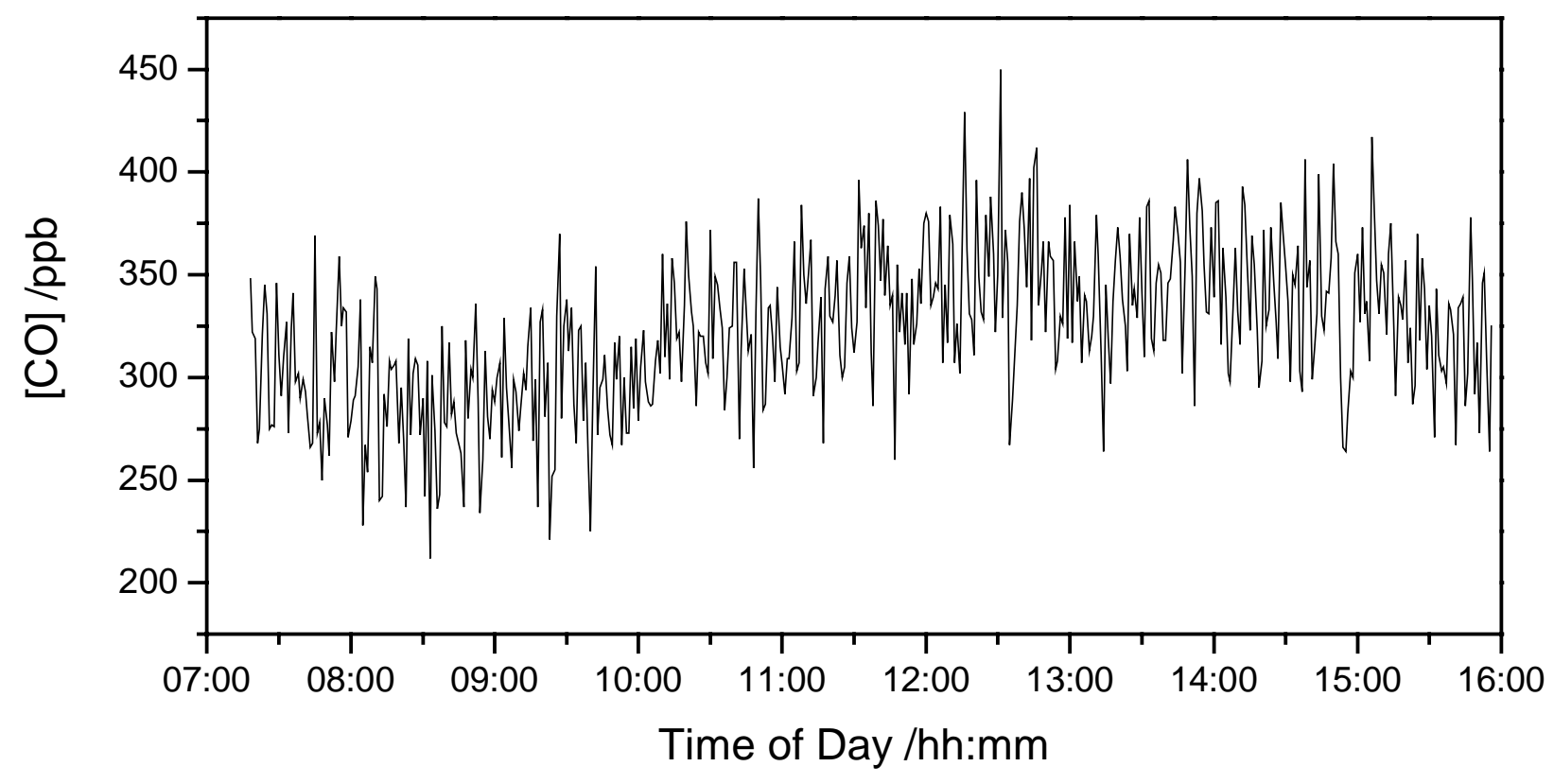

Figure S9. CO in the European Photoreactor Facility, chamber A, during the experiment on May 26, 2004. 


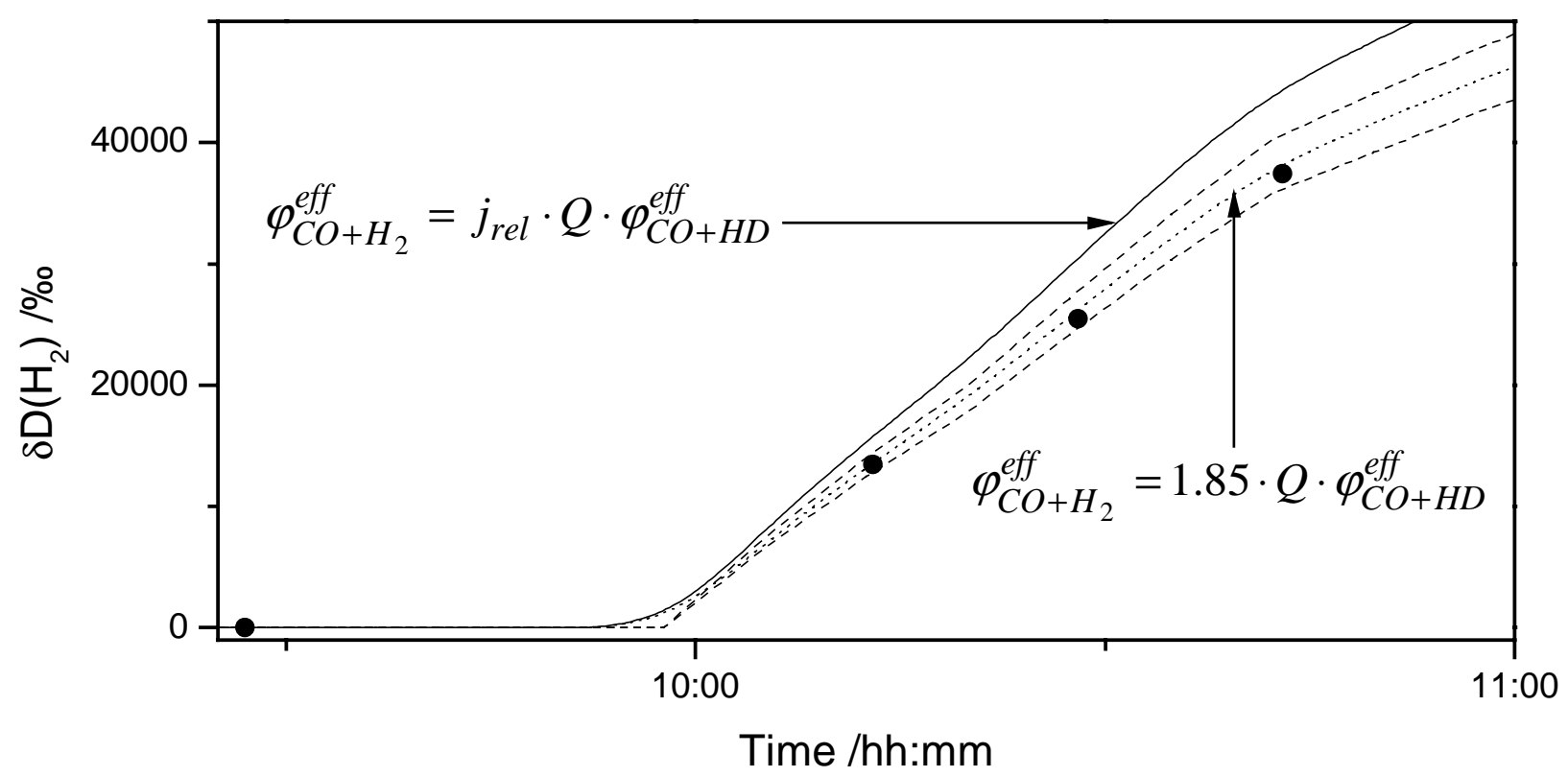

Figure S10. Observed and calculated $\delta \mathrm{D}\left(\mathrm{H}_{2}\right)$ in the EUPHORE Chamber A during photolysis of a HCHO/HCDO mixture. Data from May 24, 2004. (•) Measurements by isotope ratio mass spectrometry. The full curve corresponds to $j_{\mathrm{HCHO} \rightarrow \mathrm{CO}+\mathrm{H}_{2}} / j_{\mathrm{HCDO} \rightarrow \mathrm{CO}+\mathrm{HD}}=j_{\text {rel }}=1.59$. The dotted curve corresponds to $j_{\mathrm{HCHO} \rightarrow \mathrm{CO}+\mathrm{H}_{2}} / j_{\mathrm{HCDO} \rightarrow \mathrm{CO}+\mathrm{HD}}=1.85$. The dashed curves represent the estimated $1 \sigma$ confidence interval. 


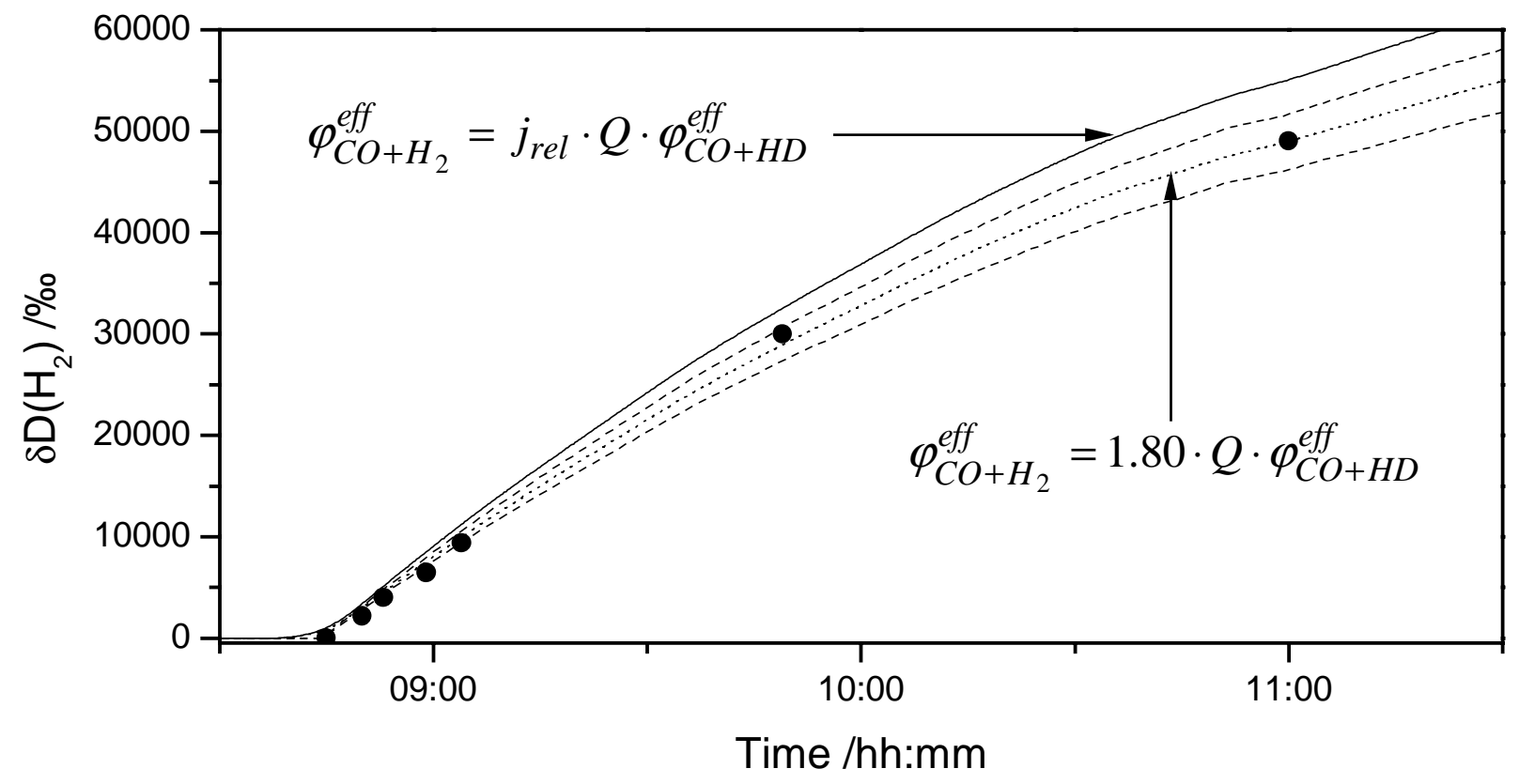

Figure S11. Observed and calculated $\delta \mathrm{D}\left(\mathrm{H}_{2}\right)$ in the EUPHORE Chamber A during photolysis of a HCHO/HCDO mixture. Data from May 27, 2004. (•) Measurements by isotope ratio mass spectrometry. The full curve corresponds to $j_{\mathrm{HCHO} \rightarrow \mathrm{CO}+\mathrm{H}_{2}} / j_{\mathrm{HCDO} \rightarrow \mathrm{CO}+\mathrm{HD}}=j_{\text {rel }}=1.60$. The dotted curve corresponds to $j_{\mathrm{HCHO} \rightarrow \mathrm{CO}+\mathrm{H}_{2}} / j_{\mathrm{HCDO} \rightarrow \mathrm{CO}+\mathrm{HD}}=1.80$. 


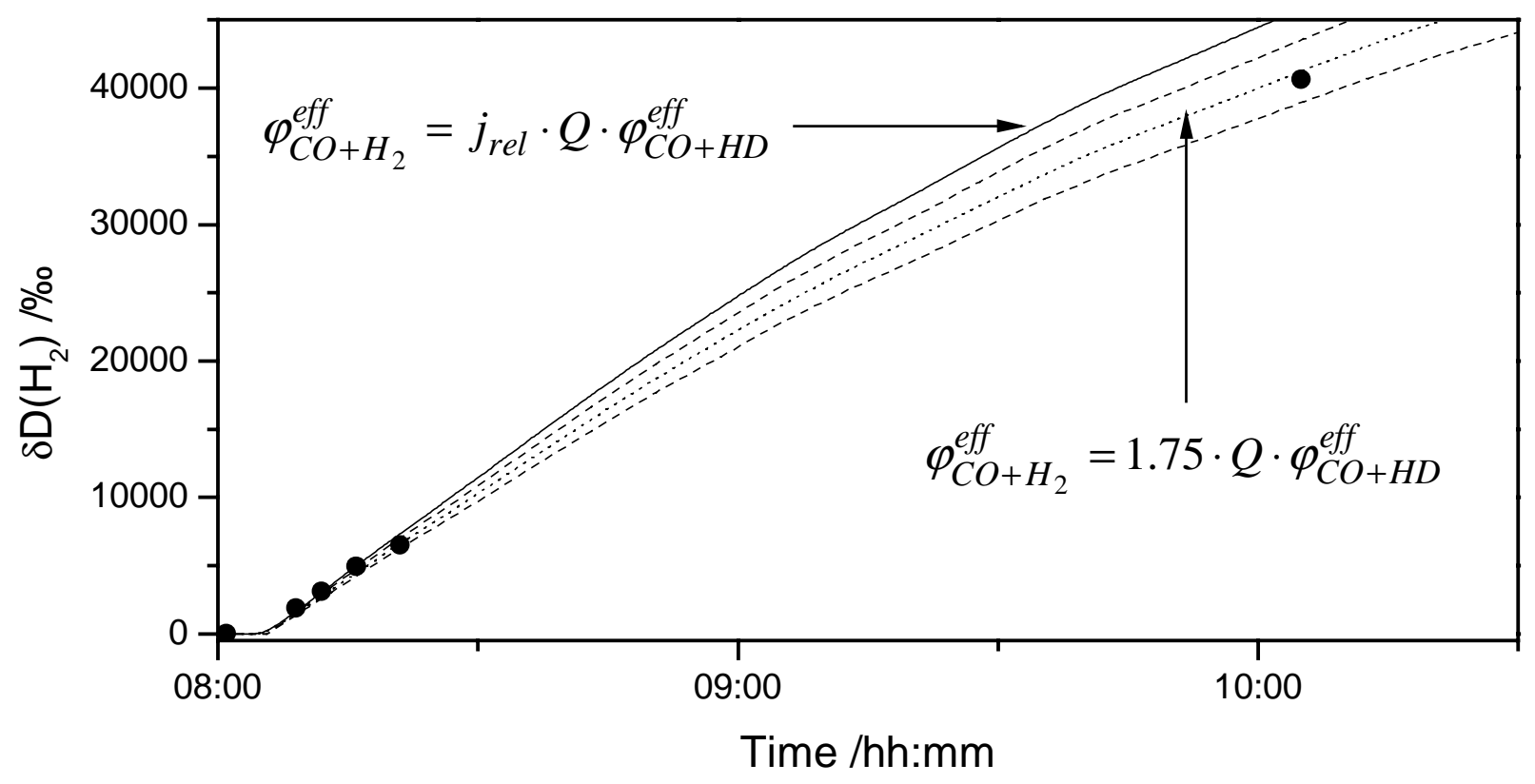

Figure S12. Observed and calculated $\delta \mathrm{D}\left(\mathrm{H}_{2}\right)$ in the EUPHORE Chamber A during photolysis of a HCHO/HCDO mixture. Data from May 28, 2004. (•) Measurements by isotope ratio mass spectrometry. The full curve corresponds to $j_{\mathrm{HCHO} \rightarrow \mathrm{CO}+\mathrm{H}_{2}} / j_{\mathrm{HCDO} \rightarrow \mathrm{CO}+\mathrm{HD}}=j_{\text {rel }}=1.57$. The dotted curve corresponds to $j_{\mathrm{HCHO} \rightarrow \mathrm{CO}+\mathrm{H}_{2}} / j_{\mathrm{HCDO} \rightarrow \mathrm{CO}+\mathrm{HD}}=1.75$. 